\title{
Variação espacial da perda de solo por erosão em diferentes superfícies geomórficas
}

\author{
Spatial variation of the soil loss for erosion in different geomorphic surfaces \\ Milton César Costa Campos ${ }^{\mathrm{I}}$ José Marques Júnior $^{{ }^{*}}$ Marcílio Vieira Martins Filho $^{\mathrm{I}}$ \\ Gener Tadeu Pereira' ${ }^{\text {II }}$ Zigomar Menezes de Souza ${ }^{\text {III }}$ Diogo Mazza Barbieri ${ }^{I}$
}

RESUMO

O objetivo deste trabalho foi estudar a influência das superfícies geomórficas na variação espacial da perda de solo por erosão na região de Pereira Barreto, São Paulo (SP). Os solos foram amostrados nos pontos de cruzamento de uma malha, georreferenciados, com intervalos de 350m, na profundidade de 0,0-0,2m, totalizando 67 pontos. Foram feitas determinações da composição granulométrica e do conteúdo de matéria orgânica. Foram avaliados os fatores de erosão locais, tais como erosividade (R), erodibilidade (K), fator topográfico (LS), uso e manejo (C), práticas conservacionistas $(P)$, potencial natural de erosão (PNE), perda de solo com e sem práticas conservacionistas ( $\left.e^{*} A\right)$, tolerância de perda de solo (T) e risco de erosão (RE). As variáveis A, PNE e RE apresentaram forte correlação espacial com o fator topográfico (LS), indicando a forte relação do relevo sobre os fatores de erosão. As perdas de solo (A $\left.e^{*} A\right)$ apresentaram comportamento coerente com a conceituação de superfícies geomórficas, evidenciando as relações de dependência do processo erosivo do solo aos ambientes geomórficos.

Palavras-chave: processos de erosão, deposição, geoestatística, relevo.

\section{ABSTRACT}

The objective of this research was to study the influence of the geomorphic surfaces in the spatial variations of the soil loss by erosion in the Pereira Barreto region, São Paulo State, Brazil. Soil samples were collected in 67 points, in a depth of 0.0-0.2m, located in a $350 \mathrm{~m}$ regular grid to measure the particle size distribution and organic matter content. The local erosion factors were determined: erosivity $(R)$, erodibility (K), topographical factor (LS), use and tillage (C), and conservation tillage $(P)$, natural potential of erosion (PNE), soil loss with and without conservation tillage (A), soil loss tolerance (T) and erosion risk (RE). The variables A, PNE and $R E$ presented great spatial correlation with the topographical factor (LS), indicating the influence of the relief on the erosion factors. The soil losses (A and A*) presented coherent behavior with the concept of geomorphic surfaces, evidencing the dependence relationships of the soil erosion process to the geomorphic environmental.

Key words: erosion process, depositions, geostatistics, relief.

\section{INTRODUÇÃO}

Superfícies geomórficas, conforme definição de RUHE et al. (1967) e DANIELS et al. (1971), são uma parte da superfície da terra que tem limites geográficos definidos e são formadas por um ou mais agentes durante um dado espaço e tempo. Estes ambientes geomórficos podem ser considerados erosionais ou deposicionais e, em uma área, pode haver ocorrência de ambos ou apenas de um ambiente geomórfico. As superfícies geomórficas mais velhas são mais estáveis e normalmente são encontradas nos topos, estando associadas a ambientes deposicionais, enquanto as superfícies mais jovens ocorrem em áreas de maior declive, sendo mais variáveis e considerados ambientes erosionais.

As variações das superfícies geomórficas e as formas do relevo têm influência direta nos processos de erosão e deposição de solos nas paisagens, fato

IDepartamento de Solos e Adubos, Faculdade de Ciências Agrárias e Veterinárias (FCAV), Universidade Estadual Paulista (UNESP), Campus de Jaboticabal, 14870-900, Jaboticabal, SP, Brasil. E-mail: marques@fcav.unesp.br. *Autor para correspondência.

IDepartamento de Ciências Exatas, FCAV, UNESP, Jaboticabal, SP, Brasil.

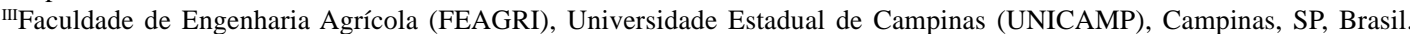


associado principalmente à inclinação do declive e à curvatura do terreno (SCHUMACHER et al., 1999; SOUZA et al., 2003). Entretanto, aspectos relacionados aos processos geomórficos e aos impactos humanos também interferem nos processos erosivos, provocando alterações (erosão e deposição) na paisagem (SCHUMACHER et al., 1999).

Apesar da importância do assunto, poucos trabalhos utilizam os conceitos de superfícies geomórficas com o enfoque nos estudos de taxas de erosão. Todavia, para que se entenda a evolução dos solos nas paisagens, faz-se necessária a compreensão dos processos erosivos, já que os mesmos são responsáveis pelo próprio desenvolvimento do solo. DANIELS et al. (1971) afirmam que esses estudos fortalecem o entendimento do desenvolvimento da paisagem, assim como melhoram a compreensão do desempenho da produção agrícola.

O trabalho desenvolvido por WANG et al. (2002) destaca a importância do estudo dos múltiplos fatores da erosão e de suas interações no solo com as posições da paisagem, pois as mesmas promovem variabilidade espacial e temporal no sistema. Os mesmos autores afirmam que a heterogeneidade do solo no tempo e no espaço depende dinamicamente e espacialmente dos atributos de um solo específico e das condições ambientais onde está inserido.

Apesar das variações do relevo influenciar os processos de erosão, a maioria das investigações é quantitativa e não relaciona o desenvolvimento do solo com os processos de erosão. Por outro lado, se as superfícies geomórficas são porções mapeáveis da paisagem com limites geográficos definidos, as avaliações da variabilidade espacial dos atributos dos solos dessas superfícies podem auxiliar no entendimento dos processos erosivos. Entretanto, estudos atuais enfatizam mais os aspectos de variabilidade temporal e destacam pouco a variação espacial dos atributos do solo ligados à erosão (OOST et al., 2000).

Nesse contexto, o uso dos conceitos de superfícies geomórficas associados às técnicas geoestatísticas apresenta-se como ferramenta eficiente para estudar os processos erosivos do solo, dada a sua variabilidade espacial e temporal, que ocorre em função da diversidade climática, pela variação do solo, e principalmente do relevo, que tem influência na susceptibilidade à erosão. Portanto, o objetivo deste trabalho foi estudar a influência das superfícies geomórficas na variação espacial das perdas de solo por erosão na região de Pereira Barreto, São Paulo (SP).

\section{MATERIAL E MÉTODOS}

A área de estudo localiza-se no Noroeste do Estado de São Paulo, no município de Pereira Barreto (SP). As coordenadas geográficas são 2041'15" de latitude sul e $51^{\circ} 03^{\prime} 45^{\prime \prime}$ de longitude oeste, com altitude média variando entre 335 e 385m acima do nível do mar. A região está localizada dentro da província geomorfológica do Planalto Ocidental, área de ocorrência dos arenitos Santo Anástacio, Grupo Bauru e transição para o basalto da Formação Serra Geral, grupo São Bento. O clima da região, segundo a classificação de Köppen, é do tipo tropical chuvoso de bosque com chuvas de verão e estiagem no inverno (Aw), com temperaturas variando entre $26,2^{\circ} \mathrm{C}$ e $21^{\circ} \mathrm{Ce}$ com precipitação média de $1.128 \mathrm{~mm}$. O relevo é predominantemente plano a suave ondulado, com declividades médias variando de 3 a $6 \%$.

Foi realizado o mapeamento de uma área de 530ha cultivada com cana-de-açúcar, utilizando-se equipamento de sistema de posicionamento global (GPS) (Figura 1). Foi elaborado o Modelo Digital de Elevação (MDE) por meio do programa Surfer, que, em conjunto, com as atividades de campo, possibilitou a identificação e a delimitação das superfícies geomórficas I, II e III (RUHE et al., 1967; DANIELS et al., 1971).

Os solos foram amostrados nos pontos de cruzamento de uma malha, georreferenciados, nas profundidades de $0,0-0,2 \mathrm{~m}, 0,2-0,5 \mathrm{~m}$ e $0,8-1,0 \mathrm{~m}$, totalizando 67 pontos. Os solos foram classificados e descritos conforme EMBRAPA(1999) e SANTOS et al. (2005). Na superfície geomórfica I, que apresenta caráter deposicional, há ocorrência do Latossolo Vermelho distrófico típico (LVd); a superfície geomórfica II é provavelmente originada a partir de processos erosionais, com ocorrência do Latossolo Vermelho eutrófico típico (LVe). A superfície geomórfica III caracteriza-se por apresentar caráter erosional residual, onde ocorrem o Latossolo Vermelho eutrófico típico (LVe), o Neossolo Litólico eutrófico típico (RLe) e o Latossolo Vermelho eutroférrico chernozêmico (LVef).

A composição granulométrica foi determinada pelo método da pipeta segundo metodologia da EMBRAPA(1997). A determinação da matéria orgânica foi realizada conforme EMBRAPA (1997). A erosão foi estimada, pela Equação Universal de Perda de Solo (EUPS), proposta por WISCHMEIER \& SMITH (1978) e adaptada por BERTONI \& LOMBARDI NETO (1990). Foram calculados dois valores de perda de solo: o primeiro foi chamado de A, sendo este o valor de perda calculado considerando o comprimento de rampa real do terreno; o segundo foi chamado de $\mathrm{A}^{*}$, sendo este para todos os pontos que não se enquadraram na classe de risco erosão muito baixa e foi reduzida a distância entre os terraços, 




Figura 1 - Modelo digital de elevação de uma área de 530ha, mostrando as superfícies geomórficas (S.G.I, S.G.II, S.G.III) mapeadas, locais das trincheiras $(\nabla)$ e os locais de amostragem de solo ( $\bigcirc)$.

calculando-se então um novo valor de perda de solo. A erosividade local das chuvas (R) foi estimada como sendo de 6340MJ mm ha-1 $\mathrm{h}^{-1} \mathrm{ano}^{-1}$, conforme método proposto por LOMBARDI NETO et al. (2000).

A erodibilidade (K) foi estimada por meio da equação proposta por DENARDIN (1990). Para determinar o fator topográfico (fator LS), utilizou-se equação proposta por WISCHMEIER \& SMITH (1978). $\mathrm{O}$ valor do fator $\mathrm{C}$ adotado para a cana-de-açúcar foi de 0,06 conforme LOMBARDI NETO \& BERTONI (1975). Para o fator $P$, foram adotados valores propostos por WISCHMEIER \& SMITH (1978), em função da declividade do terreno.

As tolerâncias de perdas de solo $(\mathrm{T})$ foram estimadas por meio do método proposto por LOMBARDI NETO \& BERTONI (1975) e modificado por BERTOL \& ALMEIDA(2000). O potencial natural de erosão (PNE) foi determinado, conforme proposto por WISCHMEIER \& SMITH (1978). O risco de erosão (RE) foi determinado e classificado de acordo com LAGROTTI(2000).

Os fatores de erosão do solo foram analisados por meio da análise estatística descritiva, calculando-se a média, a mediana, a variância, o coeficiente de variação, o coeficiente de assimetria e o coeficiente de curtose. A hipótese de normalidade dos dados foi testada pelo teste de Kolmogorov-Smirnov, por meio do programa computacional SAS.

A dependência espacial foi analisada por meio de ajustes de semivariogramas, com base na pressuposição de estacionariedade da hipótese intrínseca. Os modelos dos semivariogramas foram ajustados por meio do programa $\mathrm{GS}^{+} \mathrm{e}$, posteriormente, tais modelos foram usados no desenvolvimento de mapas de isolinhas (krigagem). Para elaboração dos mapas de distribuição espacial das variáveis, foi utilizado o programa Surfer. Com o uso da krigagem, foram gerados mapas de isolinhas (contorno) para os fatores de erosão. Posteriormente, os mapas gerados no Surfer foram exportados para o Idrisi, tornando possível a realização da regressão linear simples espacial entre mapas das variáveis estudadas, pixel-a-pixel. Os dados dos fatores de erosão foram submetidos à análise de variância, segundo um delineamento inteiramente casualizado. Para a comparação das médias, foi utilizado o teste Tukey a $5 \%$ de probabilidade.

\section{RESULTADOS E DISCUSSÃO}

Os resultados referentes à análise descritiva para os fatores de erosão são apresentados na tabela 1. Os resultados referentes ao teste KolmogorovSmirnov indicou normalidade para perda de solo com redução da distância entre os terraços $\left(\mathrm{A}^{*}\right)$ e para o fator topográfico (LS). SOUZA et al. (2005), estudando os fatores de erosão sob cultivo de cana-de-açúcar, encontrou normalidade somente para erodibilidade, com altos valores de assimetria e curtose. Os valores de assimetria estão altos para as variáveis em estudo, porém, todas as variáveis apresentam valores da média e da mediana próximos e, segundo LITTLE \& HILLS (1978), quando os valores da média, da mediana e da moda apresentam valores semelhantes, os dados apresentam ou se aproximam da distribuição normal.

A variabilidade de um atributo pode ser classificada, segundo WARRICK \& NIELSEN (1980), de acordo com a magnitude do seu coeficiente de variação (CV). Para as variáveis erodibilidade (K) e tolerância de perdas de solo (T), o CV foi médio, resultados semelhantes para a erodibilidade foram 
Tabela 1 - Estatística descritiva das variáveis, erodibilidade do solo (K), relevo (LS), potencial natural de erosão (PNE), perda de solo (A), tolerância de perda de solo (T), risco de erosão (RE) e perda de solo com a redução da distância entre osterraços (A*).

\begin{tabular}{|c|c|c|c|c|c|c|c|}
\hline \multirow[t]{2}{*}{ Estatística } & K & LS & PNE & A & $\mathrm{T}$ & $\mathrm{RE}$ & $A^{*}$ \\
\hline & $\mathrm{th} \mathrm{MJ}^{-1} \mathrm{~mm}^{-1}$ & - & $\mathrm{t} \mathrm{ha}^{-1} \mathrm{ano}^{-1}$ & t ha $^{-1}$ ano $^{-1}$ & $\mathrm{~mm}$ ano ${ }^{-1}$ & - & - \\
\hline Média & 0,05 & 0,7 & 228 & 6,7 & 8,2 & 0,8 & 6,1 \\
\hline Mediana & 0,05 & 0,6 & 199 & 5,6 & 8,1 & 0,8 & 6,0 \\
\hline Variância & $1,6 \times 10^{-5}$ & 0,1 & 15367 & 8,3 & 1,6 & 0,1 & 2,9 \\
\hline${ }^{1} \mathrm{CV}(\%)$ & 14 & 52 & 54 & 43 & 15 & 48 & 22 \\
\hline Assimetria & 1,6 & 0,2 & 1,1 & 1,1 & 1,9 & 1,3 & 0,4 \\
\hline Curtose & 0,5 & $-0,3$ & 0,2 & 0,1 & 6,6 & 0,5 & $-0,7$ \\
\hline${ }^{2} \mathrm{~d}$ & 0,4 & $0,2^{\mathrm{ns}}$ & 0,2 & 0,2 & 0,1 & 0,2 & $0,09^{\mathrm{ns}}$ \\
\hline${ }^{3} \mathrm{R}^{2}$ & 0,8 & - & 0,8 & 0,8 & 0,8 & 0,9 & 0,9 \\
\hline
\end{tabular}

${ }^{1} \mathrm{CV}=$ coeficiente de variação; ${ }^{2} \mathrm{~d}=$ teste de normalidade, ${ }^{\mathrm{n} s}$ não-significativo pelo teste de Kolmogorov-Smirnov; ${ }^{3} \mathrm{R}=$ coeficiente de regressão linear simples espacial entre o mapa da variável LS com as demais variáveis estudadas, pixel-a-pixel.

encontrados por SOUZA et al. (2005). As variáveis fator topográfico (LS), potencial natural de erosão (PNE), perda de solo (A), risco de erosão (RE) e perda de solo com redução da distância entre os terraços $\left(A^{*}\right)$ apresentaram $\mathrm{CV}$ alto, concordando com os resultados encontrados por SOUZA et al. (2003) e SOUZA et al. (2005). Observa-se que com a adoção de práticas conservacionistas, como, por exemplo, o uso de terraços como menor comprimento de rampa (A*), o CV foi da ordem de $22 \%$, com variabilidade bem menor quando comparado com a perda de solo (A), cujo CV foi de $43 \%$.

Todas as variáveis analisadas apresentaram dependência espacial (Figura 2). O modelo esférico ajustou-se à semivariância estimada de todas as variáveis estudadas, com exceção das variáveis potencial natural de erosão (PNE) e tolerância de perdas de solo (T), que se ajustaram ao modelo exponencial. SOUZA et al. (2003), estudando a influência do relevo e da erosão na variabilidade espacial de um latossolo sob cultivo de cana-de-açúcar, verificaram os modelos esférico e exponencial ajustando-se aos dados dos fatores de erosão.

Os valores do alcance relativos aos semivariogramas têm uma importância considerável na determinação do limite da dependência espacial, o que pode ser também um indicativo do intervalo entre unidades de mapeamento de solos. Com relação ao alcance da dependência espacial (Figura 2), todas as variáveis estudadas apresentaram valores bastante próximos, variando de $1572 \mathrm{~m}$ a $1936 \mathrm{~m}$, mostrando alta continuidade espacial para os fatores de erosão.

Observa-se que o mapa de krigagem do fator topográfico (LS) apresenta semelhanças com os mapas do potencial natural de erosão (PNE), perdas de solo (A), risco de erosão (RE) e perda de solo com redução da distância entre os terraços $\left(\mathrm{A}^{*}\right)$. A análise de regressão linear simples espacial entre mapas das variáveis estudadas, pixel-a-pixel, mostrou correlação do mapa do fator LS com as demais variáveis acima de 83\% (Tabela 1), confirmando que o relevo é um fator determinante nas perdas de solo por erosão. Fato justificável pela interferência do relevo sobre a drenagem, pelo movimento da água no solo e pela declividade do terreno. PARK \& BURT (2002) afirmaram que os aspectos topográficos do terreno são os principais responsáveis pela variação dos atributos do solo e, conseqüentemente, influenciam grandemente as taxas de perdas de solo por erosão.

O potencial natural de erosão (PNE), que representa o cruzamento da erosividade $(R)$ e da erodibilidade do solo (K) com o fator relevo (LS), indicando dessa forma a não-existência de cobertura vegetal e o uso de práticas conservacionistas, apresentou resultados variando entre 100 e $440 \mathrm{t} \mathrm{ha}^{-1}$ ano $^{-1}$, entretanto, os maiores resultados foram encontrados nas áreas mais declivosas, superfície geomórfica II e III (Figura 3). Estes resultados são superiores àqueles encontrados por SOUZA et al. (2003) e concordam com os valores encontrados por WANG et al. (2002), os quais afirmaram que o relevo é o fator de maior impacto na taxa de perda de solo por erosão. Os valores de perda de solo (A) variaram entre 4,0 e 10,8t ha- ${ }^{-1}$ ano $^{-1}$, sendo que os valores mais elevados foram encontrados nas áreas de ocorrência de declive mais irregular, na área de ocorrência das superfícies geomórficas II e III, demonstrando o seu caráter erosional. Para a tolerância de perda de solo (T), os valores oscilaram entre 7,3 e 9,7 $\mathrm{tha}^{-1} \mathrm{ano}^{-1}$, sendo que os menores resultados foram encontrados na superfície geomórfica I, indicando que são encontrados nessas áreas solos mais tolerantes aos processos erosivos (Figura 3). $\mathrm{O}$ risco de erosão (RE), valor adimensional, 


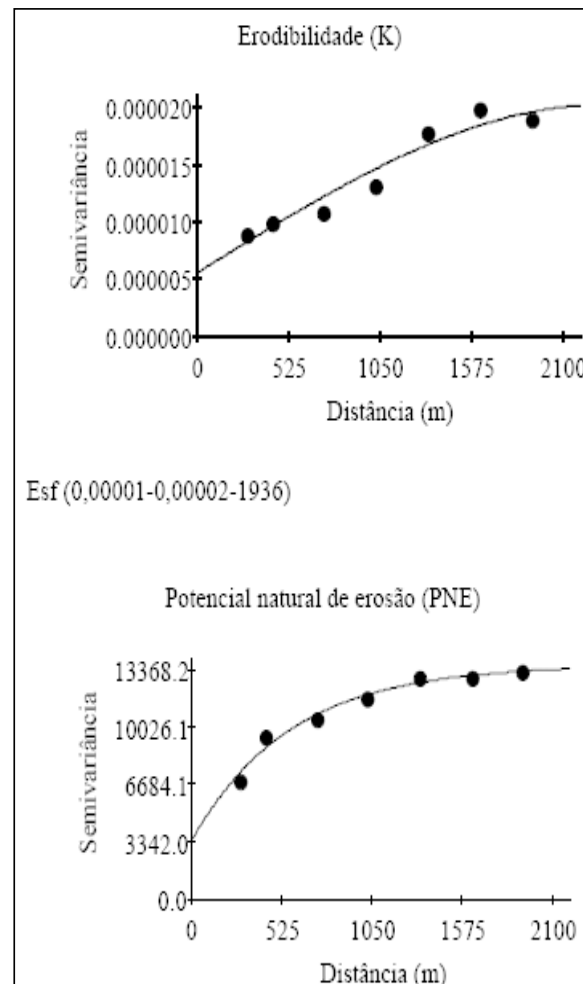

$\operatorname{Exp}(3340-13630-1716)$

Tolerância de perdas de solo $(\mathrm{T})$

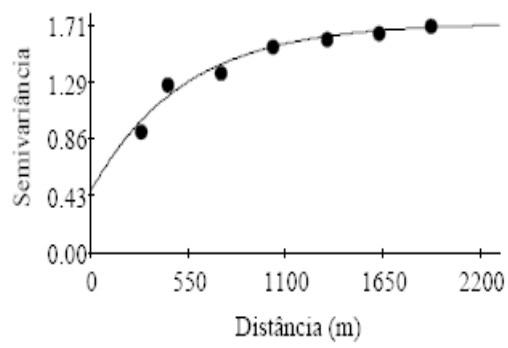

$\operatorname{Exp}(0,46-1,73-1572)$

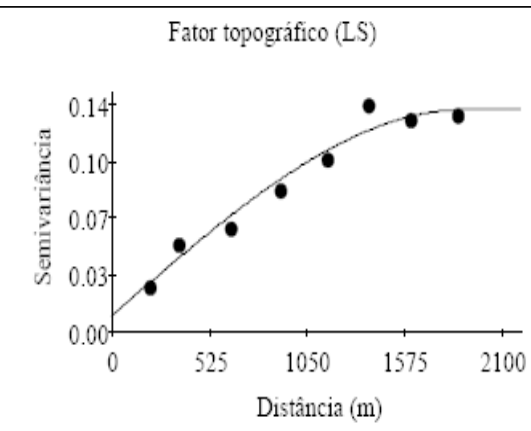

Esf $(0,009-0,13-1901)$

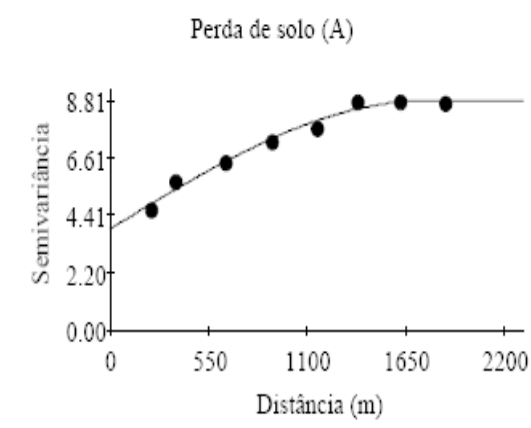

$\operatorname{Esf}(3,89-8,81-1752)$

Risco de erosão (RE)

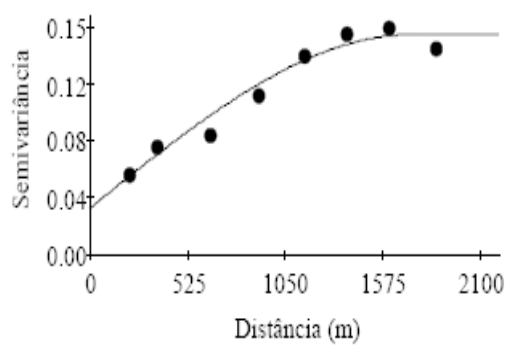

Esf $(0,03-0,15-1735)$

Figura 2 - Semivariograma da erodibilidade do solo $\left(\mathrm{t} \mathrm{h} \mathrm{MJ} \mathrm{mm}^{-1}\right)$, do fator topográfico, do potencial natural de erosão ( $\left.\mathrm{t} \mathrm{ha}{ }^{-1} \mathrm{ano}^{-1}\right)$, da perda de solo $\left(\mathrm{t} \mathrm{ha}^{-1} \mathrm{ano}^{-1}\right)$, da tolerância de perda de solo $\left(\mathrm{mm}\right.$ ano $\left.{ }^{-1}\right)$, do risco de erosão e da perda de solo com redução da distância entre os terraços. Esf e Exp $\left(C_{0} ; C_{1}+C_{0} ; a\right)$, Esf $=$ modelo esférico, $\mathrm{Exp}=$ modelo exponencial, $\mathrm{C}_{0}=$ efeito pepita; $\mathrm{C}_{1}+\mathrm{C}_{0}=$ patamar; $\mathrm{a}=$ alcance.

estabelecido em função da tolerância $(T)$, apresentou resultados da ordem de 0,45 a 1,65 (Figura 3), indicando que, nas áreas de declive mais acentuado, superfícies geomórficas II e III, a quantidade de solo que está sendo perdida é superior àquela que está sendo formada, assim sendo necessário o uso de práticas que possam diminuir esse impacto.

Para todos os pontos de amostragem de solo, foram calculados e classificados os riscos de erosão (RE) de acordo com LAGROTTI (2000), sendo assim para todos os pontos que não se enquadraram na classe de risco erosão muito baixa. Assim, devem ser estabelecidas práticas de manejo visando à conservação do solo, já que os valores da perda de solo (A) são maiores que a tolerância de perda de solo (T). Uma das formas de alterar a perda de solo foi modificar o fator topográfico (LS), diminuindo a distância entre os terraços, dessa forma, foi calculado um novo fator relevo (LS) e um novo valor de perda (A*). 

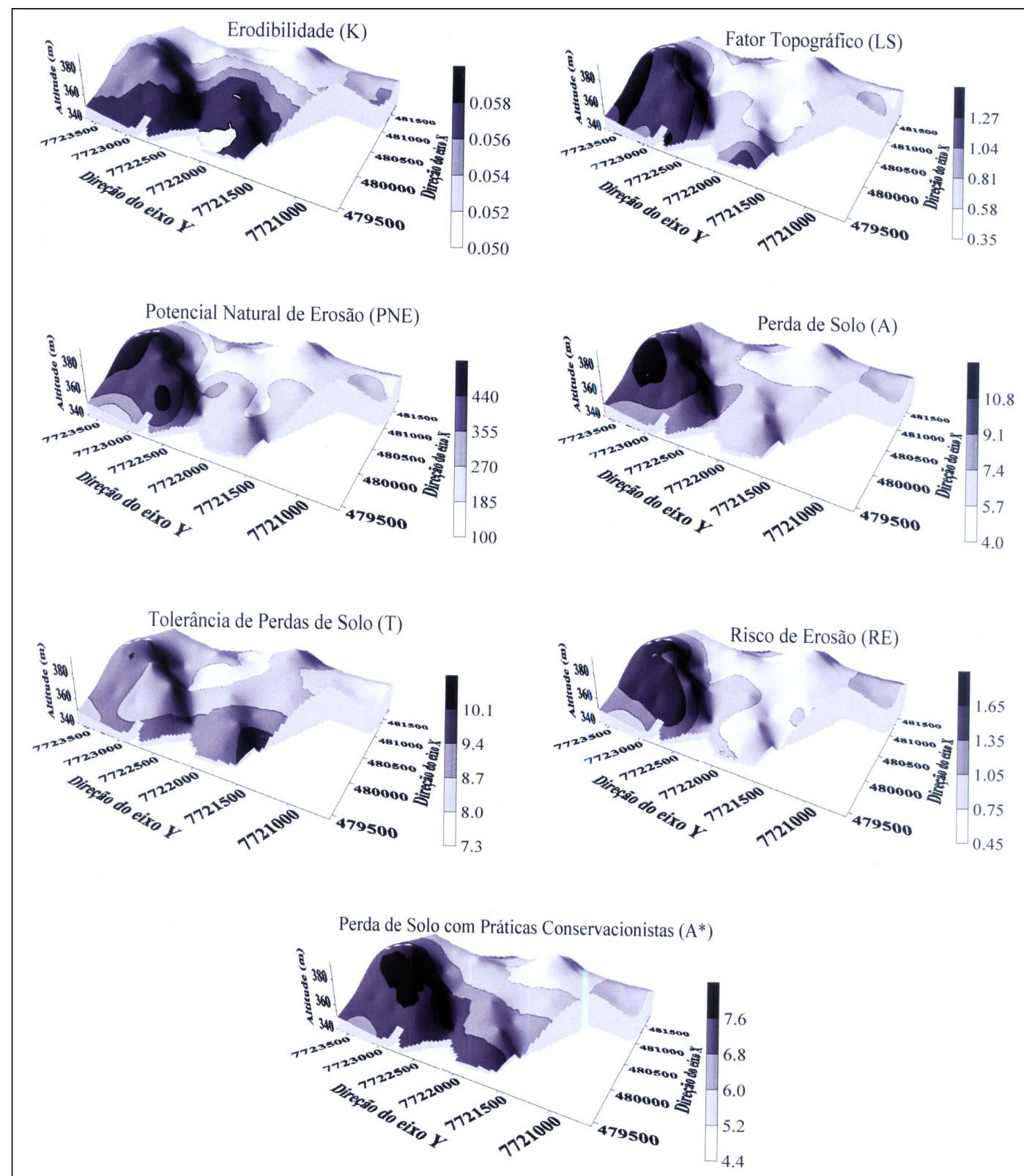

Figura 3 - Mapas de krigagem da erodibilidade do solo $\left(\mathrm{K}, \mathrm{t} \mathrm{h} \mathrm{MJ}^{-1} \mathrm{~mm}^{-1}\right)$, do fator topográfico (LS), do potencial natural de erosão (PNE, $\left.\mathrm{t} \mathrm{ha}^{-1} \mathrm{ano}^{-1}\right)$, da perda de solo $\left(\mathrm{A}, \mathrm{t} \mathrm{ha}^{-1}\right.$ ano-1 $)$, da tolerância de perda de solo (T, $\left.\mathrm{mm} \mathrm{ano}^{-1}\right)$, do risco de erosão (RE) e da perda de solo com redução da distância entre os terraços $\left(\mathrm{A}^{*}\right)$.

A perda de solo com a redução da distância entre os terraços $\left(\mathrm{A}^{*}\right)$ apresentou valores variando entre 4,4 e 8,0t ha ${ }^{-1}$ ano $^{-1}$, os quais foram inferiores aos valores de perda anteriores (Figura 3), e propiciou uma formação mais clara das faixas de perda de solo, sugerindo a implantação dos terraços. Segundo LIN et al. (2002) e XIE et al. (2003), pesquisas envolvendo variabilidade espacial e processos erosivos representam um importante avanço para os estudos da erosão do solo, pois por meio desta ferramenta são observados mais claramente aspectos ligados à topografia (grau de inclinação do declive e direção da drenagem), permitindo dessa forma a predição da taxa de erosão. De acordo com WANG et al. (2002), o uso das técnicas geoestatísticas permite não apenas uma estimativa global daquilo que realmente está acontecendo, mas uma informação dos acontecimentos locais, ou seja, tem-se um melhor detalhamento da variação espacial das perdas de solo.

Comparando as três superfícies geomórficas (Tabela 2), observa-se que as variáveis K, LS, A, T e 
Tabela 2 - Médias dos valores da erodibilidade (K), do relevo (LS), do potencial natural de erosão (PNE), da perda de solo (A), da tolerância de perda de solo $(T)$, do risco de erosão (RE) e da perda de solo com a redução da distância entre os terraços ( $\left.A^{*}\right)$ nas diferentes superfícies geomórficas.

\begin{tabular}{|c|c|c|c|c|c|c|c|}
\hline \multirow[t]{2}{*}{$\begin{array}{l}\text { Superfícies } \\
\text { Geomórficas }\end{array}$} & K & LS & PNE & A & $\mathrm{T}$ & $\mathrm{RE}$ & $A^{*}$ \\
\hline & $\mathrm{t} \mathrm{h} \mathrm{MJ}^{-1} \mathrm{~mm}^{-1}$ & - & $\mathrm{t} \mathrm{ha}^{-1}$ ano $^{-1}$ & $\mathrm{t} \mathrm{ha}^{-1} \mathrm{ano}^{-1}$ & $\mathrm{~mm}$ ano $^{-1}$ & - & - \\
\hline SG I & $0,052 \mathrm{~b}$ & $0,6 \mathrm{~b}$ & $188 \mathrm{c}$ & $5,9 \mathrm{~b}$ & $7,7 \mathrm{~b}$ & $0,8 \mathrm{a}$ & $5,5 \mathrm{~b}$ \\
\hline SG II & $0,053 \mathrm{~b}$ & $0,8 \mathrm{~b}$ & $265 \mathrm{~b}$ & $8,0 \mathrm{~b}$ & $7,9 \mathrm{~b}$ & $1,0 \mathrm{a}$ & $6,4 \mathrm{~b}$ \\
\hline SG III & $0,062 \mathrm{a}$ & 0,9 a & $312 \mathrm{a}$ & $9,5 \mathrm{a}$ & $9,4 \mathrm{a}$ & $1,0 \mathrm{a}$ & $7,1 \mathrm{a}$ \\
\hline
\end{tabular}

SG I (n = 29); SG II (n = 22); SG III (n = 16). Médias seguidas de mesmas letras na coluna não diferem entre si pelo teste de Tukey ao nível de $5 \%$.

A* apresentam o mesmo comportamento, com os maiores valores na superfície geomórfica III, que difere estatisticamente das superfícies geomórficas I e II. Resultados semelhantes foram encontrados por SOUZA et al. (2003). Para o potencial natural de erosão (PNE), as superfícies geomórficas diferiram significativamente entre si, sendo que os maiores valores são encontrados na superfície geomórfica III, enquanto que para o risco de erosão (RE) não houve diferença entre as superfícies geomórficas.

O solo da superfície geomórfica I apresenta os menores valores de perda (A e A*) e de erodibilidade do solo (K), enquanto que nas superfícies geomórficas II e III esses valores tendem a aumentar, indicando que a susceptibilidade do solo à erosão aumenta da superfície geomórfica I para a superfície geomórfica III, confirmando os conceitos apregoados por DANIELS et al. (1971), em que a superfície geomórfica I, mais antiga e estável pode ser caracterizada como superfície deposicional, enquanto que as superfícies geomórficas II e III, mais variáveis, são consideradas erosionais, ambas dependentes de sua localização na paisagem (Tabela 2 e Figura 3). Esse fenômeno é o principal responsável pela evolução da vertente por ação dominante da erosão (SOUZA et al., 2005).

De acordo com os estudos de erosão, o Latossolo Vermelho distrófico originado a partir de arenitos registram maior ação dos processos (maior taxa de perdas de solo) erosivos que os Latossolos Vermelhos eutroférricos originados a partir de basaltos (LOMBARDI NETO \& BERTONI, 1975). Entretanto, quando os estudos de erosão de solos são associados aos conceitos de superfícies geomórficas, são observados valores contrários, isto é, maiores perdas de solo são registradas nas áreas de ocorrência do Latossolo Vermelho eutroférrico de origem basáltica, em função de sua localização em superfície geomórfica de caráter erosional.

\section{CONCLUSÕES}

As perdas de solo, o potencial natural de erosão e o risco de erosão apresentaram forte relação espacial com o fator topográfico, indicando a dependência dos fatores de erosão ao relevo.

As perdas de solo (A e *A) apresentaram comportamento coerente com a conceituação de superfícies geomórficas, evidenciando as relações de dependência do processo erosivo do solo aos ambientes geomórficos.

\section{REFERÊNCIAS}

BERTOL, I.; ALMEIDA, J.A. Tolerância de perda de solo por erosão para os principais solos do Estado de Santa Catarina. Revista Brasileira de Ciência do Solo, Viçosa, v.24, n.3, p.657-668, 2000.

BERTONI, J.; LOMBARDI NETO, F. Conservação do solo. 3.ed. São Paulo: Ícone, 1990. 355p.

DANIELS, R.B. et al. The relation between geomorphology and soil morphology and genesis. Advances in Agronomy, New York, v.23, n.1, p.51-87, 1971.

DENARDIM, J.E. Erodibilidade do solo estimada por meio de parâmetros físicos e químicos. 1990. 122f. Tese (Doutorado em Solos e Nutrição de Plantas) - Curso de Pósgraduação em Agronomia, Universidade do São Paulo.

EMPRESA BRASILEIRA DE PESQUISA AGROPECUÁRIA EMBRAPA. Manual de métodos de análise de solo. 2.ed. Rio de Janeiro: Ministério da Agricultura e do Abastecimento, 1997. 212p.

EMPRESA BRASILEIRA DE PESQUISA AGROPECUÁRIA EMBRAPA. Centro Nacional de Pesquisa de Solos (Rio de Janeiro, RJ). Sistema brasileiro de classificação de solos. Brasília: Embrapa-SPI; Embrapa-CNPS, 1999. 412p.

LAGROTTI, C.A.A. Planejamento agroambiental do município de Santo Antônio do Jardim - SP: estudo de caso da microbacia hidrográfica do córrego Jardim. 2000. 
115f. Tese (Doutorado em Engenharia Agrícola) - Curso de Pós-graduação em Engenharia Agrícola, Universidade Estadual de Campinas.

LIN, C.Y. et al. Soil erosion prediction and sediment yield estimation: the Taiwan experience. Soil and Tillage Research, Amsterdam, v.68, n.2, p.143-152, 2002.

LITTLE, T.M.; HILLS, F.J. Agricultural experimentation. New York: John Wiley \& Sons, 1978. 350p.

LOMBARDI NETO, F.; BERTONI, J. Tolerância de perdas de terras para solos do Estado de São Paulo. Campinas: Instituto Agronômico, 1975. 12p. (Boletim Técnico, 28).

LOMBARDI NETO, F. et al. Sistema para cálculo da erosividade da chuva para o estado de São Paulo. Viçosa: UFV, 2000. CD-ROM.

OOST, K.V. et al. Evaluating the effects of changes in landscape structure on soil erosion by water and tillage. Landscape Ecology, Dordrecht, v.15, n.6, p.577-589, 2000.

PARK, S.J.; BURT, T.P. Identification and characterization of pedogeomorphological processes on a hillslope. Soil Science Society of American Journal, Madison, v.66, n.6, p.18971910, 2002.

RUHE, R.V. et al. Landscape evolution and soil formation in South Western Iowa. Ames: USDA, 1967. (Technical Bulletin, 1349).

SANTOS, R.D. et al. Manual de descrição e coleta de solos no campo. 5.ed. Viçosa: Sociedade Brasileira de Ciência do Solo, 2005. 100p.
SCHUMACHER, T.E. et al. Modeling spatial variation in productivity due to tillage and water. Soil and Tillage Research, Amsterdam, v.51, n.3, p.331-339, 1999.

SOUZA, C.K. et al. Influência do relevo e erosão na variabilidade espacial de um Latossolo em Jaboticabal (SP). Revista Brasileira de Ciência do Solo, Viçosa, v.27, n.6, p.10671074, 2003.

SOUZA, Z.M. et al. Variabilidade espacial de fatores de erosão em Latossolo Vermelho eutroférrico sob cultivo de cana-deaçúcar. Engenharia Agrícola, Jaboticabal, v.25, n.1, p.105114, 2005.

WANG, G. et al. Spatial uncertainty in prediction of the topographical factor for the resided universal soil loss equation (RUSLE). Transactions of the ASAE, St. Joseph, v.45, n.1, p.109-118, 2002.

WARRICK, A.W.; NIELSEN, D.R. Spatial variability of soil physical properties in the field. In: HILLEL, D. (Ed.). Applications of soil physics. New York: Academic, 1980. Cap.2, p.319-344.

WISCHMEIER, W.H.; SMITH, D.D. Predicting rainfall erosion losses: a guide to conservation planning. Washington, USDA, 1978. 57p. (USDA Agricultural Handbook, 537).

XIE, K. et al. Using contour lines to generate digital elevation models for steep slope areas: a case study of the Loess Plateau in North China. Catena, Amsterdam, v.54, p.161-171, 2003. 